\title{
Immunization of Litopenaeus vannamei shrimp against white spot syndrome virus (WSSV) by gamma-irradiated WSSV plus Vibrio paraheomolyticus
}

\author{
Motamedi-Sedeh $\mathbf{F}^{1^{*}}$, Afsharnasab $\mathbf{M}^{2}$, Heidarieh $\mathbf{M}^{1}$ \\ ${ }^{1}$ Nuclear Science and Technology Research Institute, Tehran, Iran. \\ ${ }^{2}$ Iranian Fisheries Science Research Institute, Tehran, Iran.
}

\begin{abstract}
Introduction: White spot syndrome virus (WSSV) is one of the most deadly infectious pathogens of the shrimp culture industry. Neither effective vaccines nor efficient treatments are currently available for this disease. Vibrio species are well known dominant bacterial pathogens in the shrimp ponds. As facultative pathogenic bacteria, it is possible that Vibrio spp. along with WSSV to co-infect the shrimp species such as Litopenaeus vannamei. The aim of this study was to investigate the co-administration of gamma-irradiated Vibrio paraheomolyticus as a kind of probiotic and immune-stimulator with gamma-irradiated and inactivated WSSV as an intramuscular vaccine for protection of $L$. vannamei against WSSV infection. Methods: WSSV was isolated from the infected shrimp samples and multiplied in Astacus leptodactylus crayfish. Titration of WSSV was obtained in post-larvae as $10^{5.4} \mathrm{LD}_{50} / \mathrm{ml}$. The virus was irradiated where $\mathrm{D}_{10}$ value and optimum dose of gamma ray were calculated to be 2.56 and $15 \mathrm{kGy}$, respectively. The gamma-irradiated WSSV samples, named GI-WSSV were used as a vaccine to immunize L. vannamei shrimps. The freeze-dried $V$. paraheomolyticus cultures, inactivated by gamma ray ( $8 \mathrm{kGy}$ ) were named GI-V.P and used as a probiotic. Results: Protective dose50 was calculated as 5.61 and 7.94 for the shrimp groups which were vaccinated by GI-WSSV vaccine and GI-WSSV vaccine + GI-V.P, respectively. Calculated RPS values were 73.3\%, 86.66\% and $26.66 \%$ for the GI-WSSV vaccine, GI-WSSV + GI-V.P and isolated probiotic groups, respectively. Significant differences in cumulative mortalities were observed between the vaccination groups and the positive control group $(\mathrm{P}<0.05)$. No significant difference was observed in cumulative mortalities between the two vaccination groups $(\mathrm{P}>0.05)$. Conclusion: GI-WSSV vaccine can induce immune responses in shrimps infected with WSSV and probiotic GI-V.P enhances these responses.
\end{abstract}

KEYWORDS: White Spot Syndrome Virus (WSSV), Shrimp, Gamma Irradiation, Vibrio paraheomolyticus, Probiotic.

\section{INTRODUCTION}

White spot syndrome virus (WSSV) was discovered in Southeast Asia in 1992 and is currently the most important viral pathogen that affects shrimp stocks throughout the world. This virus causes up to $100 \%$ mortality within 7 to 10 days in commercial shrimp farms, inflicting large economic losses to the shrimp farming industry. WSSV belongs to Nimaviridae family and Whispovirus genus with a double-stranded DNA genome $[1,2]$ and is considered among the greatest threats to the worldwide shrimp aquaculture industry [3]. Vaccination with immune stimulators which are widely advocated to prevent diseases in mammals and other vertebrates are unsuitable for shrimps and other invertebrates that are thought to possess only

*Corresponding Author: Farahnaz Motamedi-Sedeh, Nuclear Science and Technology Research Institute, North Kargar St., Tehran 1439951113, Iran. Email: fmotamedi@nrcam.org

Tel/Fax: (+98) 2634464075/ (+98) 2634404061 innate immunity due to their lack of antibody production. The shrimp plasma, exposed to inactivated WSSV or its sub-units, promotes virus-neutralizing responses [4] and exhibits reduced mortality upon a challenge $[1,5]$, suggesting the existence of an inducible immunity which can inhibit the subsequent infection by the same pathogen. Although the immune system of vertebrates and invertebrates are not comparable, shrimps are believed to be able to acquire immunity against pathogenic challenges. Studies on the shrimp immune response to viral infections are limited; however, the presence of virus inhibiting proteins and specific up-regulation of genes upon viral infection, have been demonstrated [6-9]. Furthermore, immune stimulations and vaccinations with inactivated Vibrio spp. protect shrimps against vibriosis and WSSV [10-12]. Vibrio species are well known in penaeid shrimp cultures as the causative agents of vibriosis. This important bacterial disease can be caused by $V$. anguillarum, $V$. alginolyticus, $V$. 
penaeicida, V. parahaemolyticus, V. harveyi and V. campbellii, in grow-out cultures and hatcheries [13, 14]. As a known facultative pathogenic bacterium, it is possible that Vibrio spp. and WSSV to co-infect shrimps regularly in the field. Vibriosis usually occurs during the first month of the shrimp cultivation in the field and may cause more than $50 \%$ mortality. So far, it has been unclear whether Vibrio spp. is an opportunistic or a primary pathogen. In this investigation, gamma-irradiated $V$. paraheomolyticus as a probiotic and immune-stimulator, was co-administrated with gamma-irradiated and inactivated WSSV as an intramuscular vaccine for protection of $L$. vannamei against WSSV.

\section{MATERIALS and METHODS}

\section{Virus stock}

The infected shrimp samples with symptoms of WSSV infection were collected from a shrimp farm in Bushehr province of Iran and WSSV infection was confirmed by nested PCR according to guideline of IQ 2000 diagnostic kit (Gene Reach Biotechnology Corp., Taiwan) $[15,16]$. The infected gill, stomach, muscle and hepato-pancreas tissues of the shrimp samples were homogenized and used for multiplication of WSSV in Astacus leptodactylus crayfish, following filtration through $0.45 \mu \mathrm{m}$ filter. The WSSV stock isolated from Iran is called WSSV/IRN/1/2010 [17-21].

\section{Gamma irradiation and inactivation of V.paraheomolyticus and WSSV}

$V$. paraheomolyticus (ATCC: 17802) was a gift from Veterinary Faculty of Tehran University. The bacterium was cultured on tryptic soy broth (TSB) with $3 \% \mathrm{NaCl}$, aliquoted in $5 \mathrm{ml}$ vials. The bacteria samples were lyophilized then irradiated by Gamma cell-Co60 source (MDS Nordian, Canada) with dose rate and activity of $4.8 \mathrm{~Gy} / \mathrm{sec}$ and $20469 \mathrm{Ci}$, respectively. Different doses of gamma rays, i.e. 2, 4, 6, 8 and $10 \mathrm{kGy}$ were used. The bacterial loads of the irradiated and unirradiated $V$. paraheomolyticus were determined as colony forming unit per milliliter (CFU/ml) and dose/ survival curve of bacterial inactivation was plotted by Origin6.1 software. The optimum dose of inactivation and $\mathrm{D}_{10}$ value (a dose of gamma irradiation that can decrease one logarithmic cycle of microorganism population) were calculated according to the curve. The gamma irradiated V. paraheomolyticus (GI-V.P) was used as a probiotic to stimulate the immune system.

The WSSV viral stock was aliquoted as $5 \mathrm{ml}$ samples which were irradiated by Gamma cell-Co60 source (MDS Nordian) with dose rate and activity of $4.8 \mathrm{~Gy} / \mathrm{sec}$ and $20469 \mathrm{Ci}$, respectively. Different doses of gamma rays, i.e. 1, 3, 5, 10, 20, 25,30 and $35 \mathrm{kGy}$ were used for irradiation of the frozen viral samples held on dry ice, and three viral samples were subjected to each irradiation gamma dose [21]. The dose/survival curve was plotted using Origin software, and $\mathrm{D}_{10}$ value and optimum doses of gamma ray for viral inactivation were obtained according to the dose/survival curve. At the end, $100 \mathrm{ml}$ of WSSV stock was irradiated with the optimum dose of gamma ray and formulated as the gamma-irradiated (GI-WSSV) vaccine.

\section{In vivo virus titration}

The virus titrations of the irradiated and unirradiated samples were conducted on Penaeus semisulcatus shrimps [20]. All shrimp in the negative control group survived, whereas mortality due to WSSV infection was observed in all groups with virus dilution during one week. All the dead shrimps were examined for WSSV by nested PCR [22]. Lethal dose 50 (LD50) was calculated by Karber method [23].

\section{Safety test}

The infectivity of the irradiated and inactivated virus samples by the optimum dose of gamma ray was determined by inoculating $\mathrm{P}$. semisulcatus post-larvae (weighing $1 \mathrm{~g}$ ) shrimps via immersion method at $20^{\circ} \mathrm{C}$ for 7 days which were then subcultured on fresh post-larvae 4 times during 4 weeks. The safety test was also carried out for irradiated $V$. paraheomolyticus by sub-culturing on Tiosulfat citrate bile salt sucrose agar (TCBS) three times.

\section{Administration of GI-WSSV vaccine and GI-V.P}

Juvenile Litopenaeus vannamei shrimps (weighing 10-15 g), were harvested from a shrimp farm which implements biosecurity measures routinely with no history of WSSV outbreak. Some of the shrimp samples were analyzed randomly by PCR to confirm the absence of WSSV contamination. Approximately, 220 shrimps were selected in 11 groups $(\mathrm{n}=$ 20) and kept in aquariums with flow-through seawater at $25-27^{\circ}$ $\mathrm{C}$ and fed at $5 \%$ of body weight per day with commercial crumbled feed before and during the experiment. The samples in groups 1-4 were injected with $50 \mu$ of 4 dilutions of GIWSSV vaccine $(1,1 / 2,1 / 4$ and $1 / 8)$ intramuscularly in the 4 th or 5th abdominal segments, respectively. The samples in groups 5-8 were co-administrated with GI-WSSV vaccine (the same above dilutions) along with GI-V.P $\left(3 \times 10^{6} / 20 \mu \mathrm{l}\right)$ intramuscularly. The vaccination was followed after a 2 -weekinterval with the same doses as a booster. On day 10 post immunization (dpi), each animal in groups 1-8 was intramuscularly challenged by injection of live WSSV (100 LD50/50 $\mu \mathrm{l})$. The groups 9, 10 and 11 were listed as negative control (injected with phosphate buffer saline (PBS)), viruspositive control (injected with live WSSV) and bacteriapositive control (injected with GI-V.P $\left.\left(3 \times 10^{6} / 20 \mu \mathrm{l}\right)\right)$, respectively. The mortality rate was recorded during 10 days in all groups, and protective dose50 (PD50) was calculated for both kinds of vaccines (i.e. GI-WSSV alone and GI-WSSV along with GI-V.P) by Reed and Muench method [24, 25]. The relative percent survival (RPS) values were also calculated according to Amend, 1981 [26].

\section{Statistical Analysis}

Analysis of variance (Oneway ANOVA) was carried out by SPSS16.0 software followed by Duncan's multiple range test. The differences were considered to be statistically significant at $\mathrm{p}<0.05$ level.

\section{RESULTS}

V. paraheomolyticus (ATCC: 17802) was cultured on TCBS agar and the bacterial load of the irradiated and unirradiated samples were determined as CFU/ml. The optimum dose of gamma ray for inactivation of the bacteria and $D_{10}$ value according to the dose/response curve were obtained to be 0.98 and $9.98 \mathrm{kGy}$, respectively (Fig.1). The frozen $V$. paraheomolyticus was inactivated by $10 \mathrm{kGy}$ of gamma radiation and the gamma-irradiated $V$. paraheomolyticus (GIV.P) was used as a probiotic to enhance the shrimps immune responses. The WSSV infection was confirmed by clinical signs and nested PCR in the infected shrimp samples which were collected from the farm. The PCR results for the tissues and haemolymph of WSSV-infected crayfish were positive (Fig. 2). 


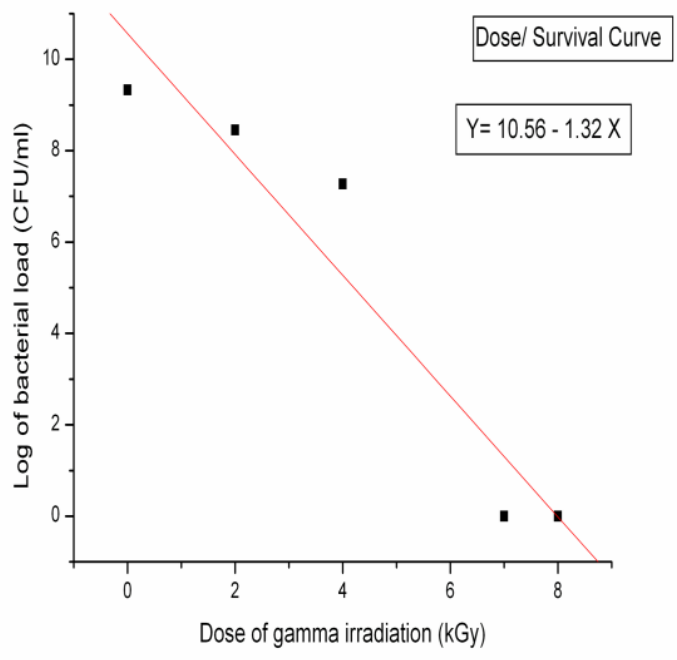

Fig. 1. Dose/response curve of gamma-irradiated V.paraheomolyticus

The LD50 of the live virus stock (WSSV/IRN/1/2010) was calculated at $10^{5.4} / \mathrm{ml}$ by the Karber formula $[23,27] . \mathrm{D}_{10}$ value and the optimum dose of gamma ray for viral inactivation were calculated according to the dose/response curve for the irradiated and unirradiated viral samples at 2.56 and $15 \mathrm{kGy}$, respectively (Fig. 3).

The viral load (LD50/ml) also decreased gradually with an increase in gamma irradiation (Table 1). Amongst moribund shrimp post-larvae (all the groups), the PCR products indicated high WSSV DNA load and negative PCR results were detected from the negative control shrimp samples (Fig. 4).

The safety test after 4 blind passages of GI-WSSV on P. semisulcatus post-larvae (weighing $1 \mathrm{~g}$ ) via immersion method was successful when no mortality was observed after inactivation by $15 \mathrm{kGy}$ of gamma ray applied to the WSSV/IRN/1/2010 titrating at $10^{5.4} \mathrm{LD}_{50} / \mathrm{ml}$.

PD50 indicated the number of protective dose in a vaccine estimated from the resistance to live virus challenge in animal groups receiving different amounts of vaccine and calculated by the Reed and Muench method. The PD50 for the GI-WSSV vaccine and GI-WSSV vaccine + GI-V.P were obtained at 5.61 and 7.94, respectively. Therefore, GI-V.P enhanced the immune responses of the shrimps when it was co-administrated with GIWSSV vaccine.

The cumulative mortalities on the $10^{\text {th }} \mathrm{dpi}$ in the groups vaccinated intramuscularly with GI-WSSV vaccine alone, GIWSSV + GI-V.P, bacteria-positive control (GI-V.P alone), negative control (PBS injection) and virus-positive control were measured as $20 \%, 10 \%, 55 \%, 0 \%$ and $75 \%$, respectively. The calculated RPS values were $73.3 \%, 86.66 \%$ and $26.66 \%$ for the GI-WSSV vaccine, GI-WSSV + GI-V.P and GI-V.P isolated groups which were vaccinated by injection, respectively (Table 2).

In cumulative mortalities were observed significant differences between both vaccination groups (i.e. GI-WSSV and GIWSSV+ GI-V.P) and the positive control group (P < 0.05). No significant difference in cumulative mortalities was observed between the two vaccination groups $(\mathrm{P}>0.05)$. As there is no significant difference between the vaccinated groups with and without GI-V.P, it can be suggested that GI-WSSV vaccine can induce immune responses in shrimps infected with WSSV while probiotic (GI-V.P) can enhance these responses although a significant effect was not detected between both vaccination groups (i.e. GI-WSSV and GI-WSSV+ GI-V.P) and the positive control group $(\mathrm{P}<0.05)$. Meanwhile, no significant difference in cumulative mortalities was observed between the two vaccination groups $(\mathrm{P}>0.05)$. As there is no significant difference between the vaccinated groups with and without GIV.P, it can be suggested that GI-WSSV vaccine can induce immune responses in shrimps infected with WSSV while probiotic (GI-V.P) can enhance these responses although a significant effect was not detected.

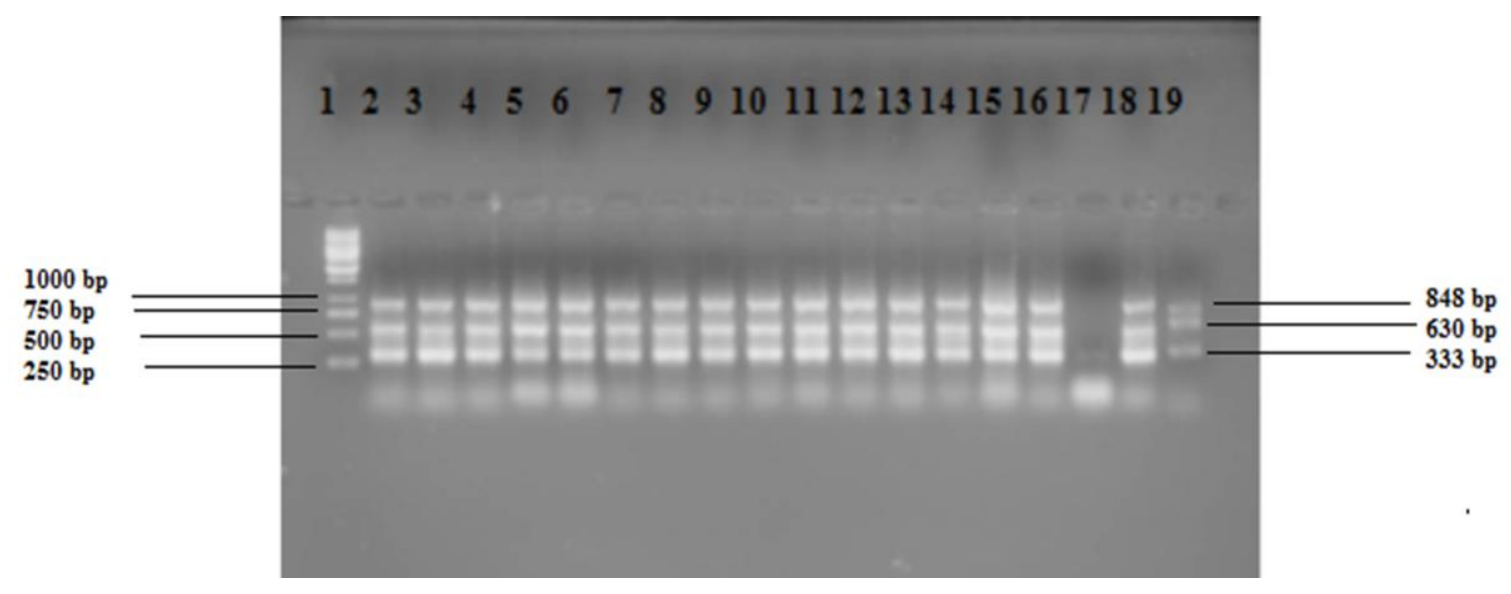

Fig. 2. The results of nested PCR for the tissues and haemolymph of WSSV-infected crayfish; Lane 1: DNA ladder (10000-250 bp, Fermentas SM0313); Lanes 2-16: PCR results of the tissues and haemolymph of WSSV-infected crayfishes; Lanes 18-19: DNA Ladder of IQ 2000 diagnostic kit (From top to bottom: 848, 630 and 333 bp), Lane 17: negative control. 


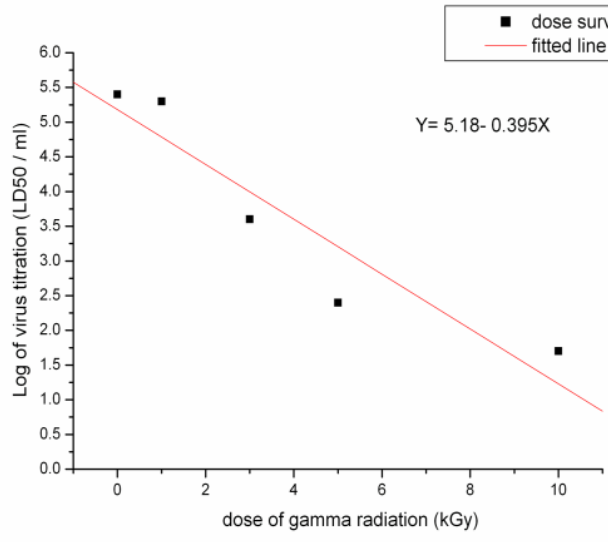

Fig. 3. Dose/response curve of gamma-irradiated and un-irradiated WSSV samples.

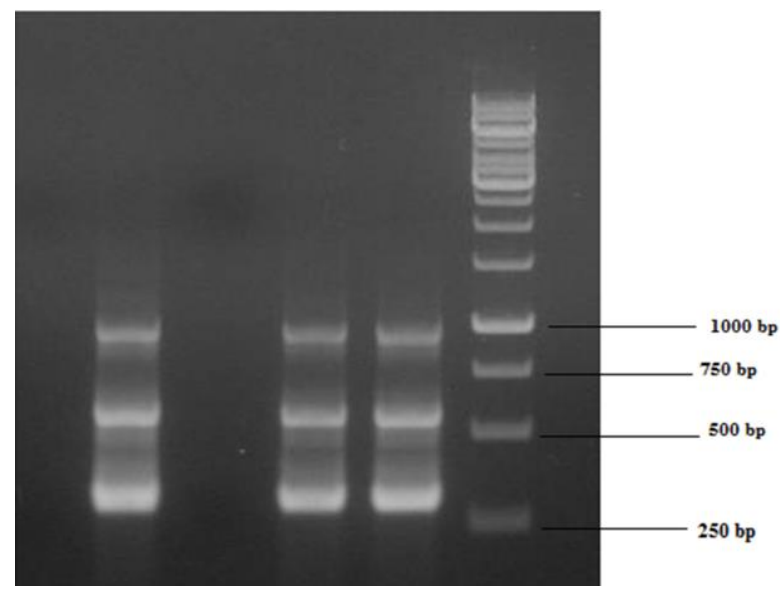

Fig. 4. PCR results of moribund shrimp post-larvae after inoculation of WSSV; Lane 1, 3 and 4: infected shrimp, lane 2: negative control shrimp, lane 5: DNA ladder

Table 1. Virus titers for irradiated and naive WSV/IRN/1/2010 preparations

\begin{tabular}{|c|c|c|c|c|c|c|c|c|c|}
\hline Dose of gamma irradiation $(\mathrm{kGy})$ & 0 & 1 & 3 & 5 & 10 & 20 & 25 & 30 & 35 \\
\hline Virus titration $\left(\mathbf{L D}_{\mathbf{5 0}} / \mathrm{ml}\right)$ & $\mathbf{1 0}^{\mathbf{5 . 4}}$ & $\mathbf{1 0}^{\mathbf{5 . 3}}$ & $\mathbf{1 0}^{\mathbf{3 . 6}}$ & $\mathbf{1 0}^{\mathbf{2 . 4}}$ & $\mathbf{1 0}^{\mathbf{1 . 7}}$ & $\mathbf{1 0}^{\mathbf{1 . 5}}$ & $\mathbf{1 0}^{\mathbf{1 . 5}}$ & $\mathbf{1 0}^{\mathbf{1 . 5}}$ & $\mathbf{1 0}^{\mathbf{1 . 5}}$ \\
\hline
\end{tabular}

Table 2. Resistance against experimental WSSV/IRN/1/2010 infection in shrimps vaccinated with GI-WSSV vaccine plus GI-V.P

\begin{tabular}{|c|c|c|c|c|}
\hline \multirow{2}{*}{ Vaccine groups } & \multicolumn{3}{|c|}{ Route of administration: Injection (IM) } \\
\cline { 2 - 5 } & Dead/tested & Mortality (\%) & RPS (\%) & p-value \\
\hline GI-WSSV vaccine & $4 / 20$ & 20 & 73.33 & $<0.05$ \\
\hline GI-WSSV vaccine + GI-V.P & $2 / 20$ & 10 & 86.66 & $<0.05$ \\
\hline GI-V.P (probiotic) & $11 / 20$ & 55 & 26.66 & $<0.05$ \\
\hline Virus positive control & $15 / 20$ & 75 & 0 & $<0.05$ \\
\hline Negative control & $0 / 20$ & 0 & 100 & \\
\hline
\end{tabular}

\section{DISCUSSION}

Ionizing radiation is a highly reliable procedure in which electromagnetic radiation such as gamma rays, emitted from Cobalt 60 or Cesium 137 isotopes, is used for inactivation of microorganisms such as viruses, with the advantage of minimal molecular changes to the viral proteins and structures [28]. Virus inactivation by gamma and electron irradiations follows physical laws, including an exponential law that means an organism will probably survive irrespective of the irradiation dose. Sterility assurance level or SAL is the value of such a probability. SAL is in general a value of $10^{-6}$ (a one in a million chance of having live microorganisms) [29]. When inactivated vaccine are going to be prepared, the most important parameter is the minimum inactivation endpoint which is dependent on parameters such as the inactivation rate, dose of irradiation and virus titer per volume unit [27]. Ionizing radiations such as gamma rays can damage the molecular structure of viral nucleic acids that cause virucidal effect $[28,30,31]$. A great deal of advanced research has recently been devoted to inactivation of viruses, bacteria and parasites by ionizing radiation. For instance, we have previously shown that gamma-irradiated vaccine against FMDV type O/IRN/1/2007 and FMDV type
A/87/IRN could induce protective immune responses in mice and guinea pigs [32]. Furthermore, Lombardo and Smolko [33] have studied gamma-irradiated FMDV with unaltered antigenicity as an inactivated vaccine. In addition, the ability of gamma-irradiated and inactivated influenza virus to induce both a strong humoral and a potent $\mathrm{T}$-cell response should encourage the consideration of this technique in the search for a promising vaccine against other viral diseases [34]. Studies about the shrimp immune responses against the viral infections are limited, however the presence of virus inhibiting proteins and specific up-regulation of shrimp genes upon viral infections have been demonstrated $[10,11,35]$. In vivo experiments with Penaeus japonicus have shown the presence of a quasi-immune response when the survivors of both the natural and the experimental WSSV infections were re-challenged with WSSV [4]. Research has shown that plasma from the surviving infected shrimps could neutralize WSSV, 20 to 60 days after the infection [36]. These outcomes suggest that a form of adaptive immune response could exist in shrimps [19]. Moreover, a study on the antiviral immunity in crustaceans has shown the induction of shrimp genes associated with its ability to survive the viral infections. However, it is not clear which of these shrimp genes would lead to the production of the antiviral substances [37]. Phouc et al. have reported the synergistic effect 
of WSSV and V. campbellii on the development of the disease in specific pathogen-free L. vannamei shrimp [12].

According to this study, GI-WSSV can induce immune responses in shrimp infected with WSSV, and probiotic (GIV.P) can enhance these responses. This remark lights up the way for designing practical strategies to control WSSV infections as well as other invertebrate pathogens. Furthermore, the co-administration of GI-V.P as a probiotic could enhance the immunity against WSSV. Therefore, following more practical routes of vaccine administration such as bathimmersion or oral vaccination might lead to a highly promising vista of the next research domains in this field. On this regard, studies on the post-larvae vaccination in shrimp hatcheries, vaccine shelf life and duration of the immunity against WSSV after the vaccination are highly suggested.

\section{ACKNOWLEDGEMENT}

The authors express their gratitude to the Research and Technology Deputy of the Nuclear Science and Technology Research Institute and Research Deputy of the Fishery Science and Research Institute of Iran and Shrimp Research School. We also express our gratitude to Roshan Zamir, MA, for English language editing.

\section{CONFLICT OF INTEREST}

The authors declare that they have no conflict of interest.

\section{REFERENCES}

1. Namikoshi A, Wu J, Yamashita T, Nishizawa T, Nishioka T, Arimoto M et al. Vaccination trials with Penaeus japonicus to induce resistance to white spot syndrome virus. aquaculture. 2004;229(1-4):25-35.

2. Afsharnasab M, Kakoolaki S, Afazli F. The Status of white spot syndrome virus (WSSV) in Islamic Republic of Iran. Iranian Journal of Fisheries Sciences. 2014;13(4):1021-55.

3. Amar E, Faisan J. Efficacy of an inactivated vaccine and nutritional additives against white spot syndrome virus (WSSV) in shrimp (Penaeus monodon). The Israeli journal of aquaculture 2011;63(1):1-9.

4. Venegas C, Nonaka L, Mushiake K, Nishizawa T, Muroga K. Quasiimmune response of Penaeus japonicus to penaeid rod-shaped DNA virus (PRDV). Diseases of aquatic organisms. 2000;42(2):83-9.

5. Rosamma P, Bright Singh I, Manjusha M, Somnath Pai S. Fenneropenaeus indicus is protected from white spot disease by oral administration of inactivated white spot syndrome virus. 2005;66:265-70.

6. Alabi A, Jones D, Latchford J. The efficacy of immersion as opposed to oral vaccination of Penaeus indicus larvae against Vibrio harveyi. Aquaculture. 1999;178(1):1-11.

7. Itami T, Yan Y, Takahashi Y. Efficacy of vaccination against vibriosis in cultured kuruma prawns Penaeus japonicus. Journal of Aquatic Animal Health. 1989;1:234-42.

8. Teunissen O, Faber R, Booms G, Latscha T, Boon J. Influence of vaccination on vibriosis resistance of the giant black tiger shrimp Penaeus monodon (Fabricius). Aquaculture. 1998;164(1):359-66.

9. Pan J, Kurosky A, Xu B, Chopra AK, Coppenhaver DH, Singh IP et al. Broad antiviral activity in tissues of crustaceans. Antiviral research. 2000;48(1):39-47.

10. Rojtinnakorn J HI, Itami T, Takahashi Y, Aoki T. Gene expression in haemocytes of kuruma prawn, Penaeus japonicus, in response to infection with WSSV by EST approach. Fish Shellfi Immuno. 2002;13(1):69-83.

11. Roux MM, Pain A, Klimpel KR, Dhar AK. The lipopolysaccharide and $\beta$-1, 3-glucan binding protein gene is upregulated in white spot virusinfected shrimp (Penaeus stylirostris). Journal of virology. 2002;76(14):7140-9.

12. Phuoc L, Corteel M, Nauwynck H, Pensaert M, Alday Sanz V, Van Den Broeck W et al. Increased susceptibility of white spot syndrome virusinfected Litopenaeus vannamei to Vibrio campbellii. Environmental microbiology. 2008;10(10):2718-27.
13. Sindermann C, Lightner D. Disease Diagnosis and Control in North American Marine Aquaculture. Elsevier Scientific 1988.

14. Lavilla-Pitogo CR, Baticados MCL, Cruz-Lacierda ER, Leobert D. Occurrence of luminous bacterial disease of Penaeus monodon larvae in the Philippines. Aquaculture. 1990;91(1-2):1-13.

15. Afsharnasab M, Mortezaei R, Yegane V, Kazemi B. Gross sign, histopathology and polymerase chain reaction observations of white spot syndrome virus in shrimp specific pathogen free Litopeneaus vannamei in Iran. Asian Journal of Animal and Veterinary Advances. 2009;4(6):297-305. 16. Afsharnasab M, Dashtiannasab A, Yeganeh V, Soltani M. Incidence of white spot disease (WSD) in Penaeus indicus Farms in Bushehr province, Iran. Iranian Journal of Fisheries Sciences. 2007;7(1):15-26.

17. van Hulten MC, Witteveldt J, Snippe M, Vlak JM. White spot syndrome virus envelope protein VP28 is involved in the systemic infection of shrimp. Virology. 2001;285(2):228-33.

18. Du H, Xu Z, Wu X, Li W, Dai W. Increased resistance to white spot syndrome virus in Procambarus clarkii by injection of envelope protein VP28 expressed using recombinant baculovirus. Aquaculture. 2006;260(1):39-43.

19. Witteveldt J, Cifuentes CC, Vlak JM, van Hulten MC. Protection of Penaeus monodon against white spot syndrome virus by oral vaccination. Journal of virology. 2004;78(4):2057-61.

20. Motamedi Sedeh F, Afsharnasab M, Heidarieh M, Shafaee S, Rajabifar $\mathrm{S}$, Dashtiannasab A et al. Titration of the Iranian White Spot Virus isolate, on Crayfish Astacus leptodactylus and Penaeus semisulcatus. Iranian Journal of Fisheries Sciences. 2012;11(1):145-55.

21. Heidareh M, Sedeh FM, Soltani M, Rajabifar S, Afsharnasab M, Dashtiannasab A. White spot syndrome virus inactivation study by using gamma irradiation. Chinese Journal of Oceanology and Limnology. 2014;32(5):1024-8.

22. Witteveldt J, Vlak JM, van Hulten MC. Protection of Penaeus monodon against white spot syndrome virus using a WSSV subunit vaccine. Fish \& shellfish immunology. 2004;16(5):571-9.

23. Karber G. $50 \%$ end-point calculation. Arch Exp Pathol Pharmak. 1931;162:480-3.

24. Reed LJ, Muench H. A simple method of estimating fifty per cent endpoints. American journal of epidemiology. 1938;27(3):493-7.

25. Pay T, Hingley P. Foot and mouth disease vaccine potency test in cattle: the interrelationship of antigen dose, serum neutralizing antibody response and protection from challenge. Vaccine. 1992;10(10):699-706.

26. Amend DF. Potency testing of fish vaccines. In: Anderson DP, Hennessen W, editors. Fish biologics: serodiagnostics and vaccines. Switzerland: S. Karger,; 1981. p. 447-54.

27. Motamedi-Sedeh F, Soleimanjahi H, Jalilian AR, Mahravani H, Shafaee $\mathrm{K}$, Sotoodeh $\mathrm{M}$ et al. Development of Protective Immunity against Inactivated Iranian Isolate of Foot-and-Mouth Disease Virus Type $\mathrm{O} / \mathrm{IRN} / 2007$ Using Gamma Ray-Irradiated Vaccine on BALB/c Mice and Guinea Pigs. Intervirology. 2015;58(3):190-6.

28. International Atomic Energy Agency. Sterility assurance level; in: Guidelines for Industrial Radiation Sterilization of Disposable Medical Products (Cobalt-60 Gamma Irradiation). Vienna: IAEA1990. Report No.: 539.

29. Da Silva Aquino KA. Sterilization by Gamma Irradiation. In: Adrovic PF, editor. Gamma Radiation. 2012. p. 171-4.

30. Ginoza W. Inactivation of viruses by ionizing radiation and by heat. Methods in virology. 1968;4:139-209.

31. Rohwer RG. Scrapie infectious agent is virus-like in size and susceptibility to inactivation. Nature. 1984;308:658-62.

32. Motamedi-Sedeh F, Khorasani A, Shafaee K, Fatolahi H, Arbabi K. Preparation of FMD type A87/IRN inactivated vaccine by gamma irradiation and the immune response on guinea pig. Indian journal of microbiology. 2008;48(3):326-30.

33. Lombardo J, Smolko E. A biotechnological project with a gamma radiation source of 100,000 ci. International Journal of Radiation Applications and Instrumentation Part C Radiation Physics and Chemistry. 1990;35(4):585-9.

34. Alsharifi M, Müllbacher A. The [gamma]-irradiated influenza vaccine and the prospect of producing safe vaccines in general. Immunology and cell biology. 2010;88(2):103-4.

35. Baron S. Broad antiviral activity in tissue of crustaceans. Antiviral Research. 2000;48:39-47.

36. Wu J, Nishioka T, Mori K, Nishizawa T, Muroga K. A time-course study on the resistance of Penaeus japonicus induced by artificial infection with white spot syndrome virus. Fish \& shellfish immunology. 2002;13(5):391403 . 
37. Liu H, Söderhäll K, Jiravanichpaisal P. Antiviral immunity in crustaceans. Fish \& shellfish immunology. 2009;27(2):79-88. 